\title{
Sarcopenia as a prognostic factor in patients with recurrent pancreatic cancer: a retrospective study
}

Teruhisa Sakamoto*, Takuki Yagyu, Ei Uchinaka, Kozo Miyatani, Takehiko Hanaki, Kyoichi Kihara, Tomoyuki Matsunaga, Manabu Yamamoto, Naruo Tokuyasu, Soichiro Honjo and Yoshiyuki Fujiwara

\begin{abstract}
Background: Sarcopenia is a prognostic factor in various cancers. However, the impact of sarcopenia in patients with recurrent pancreatic cancer remains unclear. This study evaluated the prognostic significance of sarcopenia in patients with recurrent pancreatic cancer.

Methods: Seventy-four patients who developed postoperative recurrence of pancreatic cancer after undergoing pancreatectomies were enrolled. Sarcopenia in these patients was defined according to the psoas muscle index (PMI) measured via computed tomography at the third vertebra.

Results: The mean PMls at the time of recurrence were $4.47 \pm 1.27 \mathrm{~cm}^{2} / \mathrm{m}^{2}$ for men and $3.26 \pm 0.70 \mathrm{~cm}^{2} / \mathrm{m}^{2}$ for women. Of the 74 patients, 65 (87.8\%) were diagnosed with sarcopenia with low PMI. The 2-year post-recurrence survival curve in the sarcopenia group was significantly worse than that in the non-sarcopenia group $(P=0.034)$. Multivariate analysis revealed that sarcopenia at the time of recurrence was an independent prognostic factor $(P=$ 0.043 ) along with a high neutrophil-to-lymphocyte ratio $(P=0.004)$, early recurrence $(P=0.001)$, and chemotherapy after recurrence $(P=0.005)$ in patients with recurrent pancreatic cancer. Furthermore, the area under the curve (AUC) of the combination of sarcopenia and time to recurrence for predicting 2-year survival was 0.763 , which was much higher than that of sarcopenia alone (AUC $=0.622$ ).
\end{abstract}

Conclusions: Sarcopenia is a useful prognostic factor in patients with recurrent pancreatic cancer. The combination of sarcopenia and time of recurrence may more accurately predict post-recurrence survival than can sarcopenia alone.

Keywords: Recurrent pancreatic cancer, Sarcopenia, Prognosis

\section{Introduction}

Prognosis in cancer patients is multifactorial. Tumorspecific factors and individual patient characteristics are risk factors for prognosis in patients with various malignant diseases. Many studies have reported that evaluating the body composition can help determine survival outcomes in cancer patients [1-4].

\footnotetext{
* Correspondence: tesakamo@tottori-u.ac.jp

Division of Gastrointestinal and Pediatric Surgery, Department of Surgery, School of Medicine, Tottori University Faculty of Medicine, 36-1 Nishi-cho, Yonago 683-8504, Japan
}

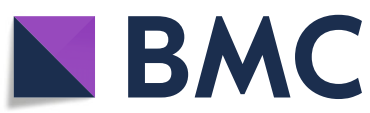

(c) The Author(s). 2020 Open Access This article is licensed under a Creative Commons Attribution 4.0 International License, which permits use, sharing, adaptation, distribution and reproduction in any medium or format, as long as you give appropriate credit to the original author(s) and the source, provide a link to the Creative Commons licence, and indicate if changes were made. The images or other third party material in this article are included in the article's Creative Commons licence, unless indicated otherwise in a credit line to the material. If material is not included in the article's Creative Commons licence and your intended use is not permitted by statutory regulation or exceeds the permitted use, you will need to obtain permission directly from the copyright holder. To view a copy of this licence, visit http://creativecommons.org/licenses/by/4.0/ The Creative Commons Public Domain Dedication waiver (http://creativecommons.org/publicdomain/zero/1.0/) applies to the data made available in this article, unless otherwise stated in a credit line to the data. age-related decrease in skeletal muscle mass [5]. Sarcopenia was later defined as a syndrome characterized by progressive and generalized loss of skeletal muscle mass and strength with adverse outcomes, including physical disability, poor quality of life, and death. Sarcopenia was further classified into primary sarcopenia, caused only by aging, and secondary sarcopenia, with causes such as physical hypoactivity, malnutrition, inflammatory disease, the endocrine system, and malignancy $[6,7]$. Previous reports suggest that sarcopenia in cancer patients 
might reflect hypercatabolism of the skeletal muscle promoted by aggressive biological behaviors from cancer [8-10]. In cancers of the digestive system, sarcopenia is generally recognized as an accurate and quantitative marker of frailty and as a prognostic risk factor [11-15].

Pancreatic cancer remains the cancer with the poorest prognosis among gastrointestinal malignancies despite advanced surgical techniques, development of perioperative treatment, and progress in systemic therapies such as chemotherapy $[16,17]$. Preoperative sarcopenia is closely associated with both preoperative cancer stage and poor prognosis in pancreatic cancer [18-20]. Sarcopenia is a prognostic factor in patients with advanced pancreatic cancer because it impairs the response to chemotherapy $[21,22]$. However, the impact of sarcopenia for prognosis after recurrence in patients who underwent pancreatectomies for pancreatic cancer remains unclear.

Therefore, this study examined the prognostic significance of sarcopenia in patients with recurrent pancreatic cancer using the psoas muscle index (PMI), a comparatively easy method for representing skeletal muscle volume among the measurements used to evaluate sarcopenia [23].

\section{Patients and methods}

\section{Patients}

We retrospectively reviewed the medical records of 114 patients who were histopathologically diagnosed with pancreatic ductal adenocarcinoma and had undergone pancreatectomies with regional lymphadenectomy at Tottori University Hospital between January 2005 and February 2018. Of these patients, 74 had developed postoperative recurrence as of March 2020 and were enrolled in this study. All patients in this study were of Japanese ethnicity.

Patients were diagnosed with postoperative recurrence via diagnostic imaging, which was performed periodically and included ultrasonography, computed tomography, magnetic resonance imaging, and if needed positron emission tomography, and via the tumor marker, carbohydrate antigen 19-9. Causes of death and patterns of recurrence were determined by reviewing medical records or by direct inquiry with family members. Data on the pathological findings of specimens obtained from the initial pancreatic resection, such as primary tumor size, localization, lymph node metastasis, and histological grading, were collected as per the 8th edition of the Union for International Union Against Cancer classification system of tumor node metastasis [24]. Clinical characteristics, such as age at time of recurrence, sex, chemotherapy after recurrence, time to recurrence after initial surgery, carbohydrate antigen 19-9, and neutrophil-to-lymphocyte ratio as an inflammatory indicator, were obtained from patients' medical records. Early recurrences were defined as recurrences within 12 months after the initial surgery; late recurrences were those occurring later than 12 months after the initial surgery [25].

\section{Assessment of PMI and definition of sarcopenia}

PMI was calculated according to a previous report [23]. Briefly, to determine the PMI value, computed tomography images at the time of recurrence were analyzed using SYNAPSE VINCENT (Fujifilm, Tokyo, Japan). The cross-sectional areas of bilateral psoas muscles at the third lumbar vertebra (L3) were measured by manual tracing. Then, the PMI at the time of recurrence was calculated by normalizing the cross-sectional areas of bilateral psoas muscles to the height $\left(\mathrm{cm}^{2} / \mathrm{m}^{2}\right)$. Three authors measured the cross-sectional areas of bilateral psoas muscles at the third lumbar vertebra (L3), and the mean value was used for the analyses.

Sarcopenia was defined as a PMI $<6.36 \mathrm{~cm}^{2} / \mathrm{m}^{2}$ for men and $<3.92 \mathrm{~cm}^{2} / \mathrm{m}^{2}$ for women [23].

\section{Statistical analysis}

To evaluate between-group differences, chi-square or Fisher's exact probability tests were used for categorical variables, and the Mann-Whitney $U$ test was used for continuous variables. Post-recurrence survival curves were calculated using the Kaplan-Meier method, and differences among survival curves were estimated with log-rank tests. Univariate and multivariate analyses with Cox proportional hazards models were performed to determine the significant prognostic factors for overall survival after recurrence. The areas under the curves (AUCs) with respect to predicting 2-year survival were determined using receiver operating characteristic analyses. Variables with $P<0.2$ were included in the multivariate analysis. $P$ values $<0.05$ were considered statistically significant. All statistical analyses were conducted using the SPSS software (SPSS for Windows version 24; IBM Corp., Armonk, NY, USA).

\section{Results}

The median follow-up time after recurrence was 10.5 (range 0.3-84.5) months for all patients in this study. Fifty-seven of 74 patients (77.0\%) with recurrence received chemotherapy. The first-line chemotherapy was performed as follows: 42 patients received a gemcitabinebased regimen (gemcitabine alone or gemcitabine plus S-1 or gemcitabine plus nab-paclitaxel), 13 received S-1 alone, 1 received uracil-tegafur, and 1 received modified FOLFIRINOX. Second-line chemotherapy was administered to 17 of 57 patients (29.8\%) who experienced disease progression. The other patients, except those who received chemotherapy, underwent best supportive care.

The mean PMIs at the time of recurrence were $4.47 \pm$ $1.27 \mathrm{~cm}^{2} / \mathrm{m}^{2}$ for men and $3.26 \pm 0.70 \mathrm{~cm}^{2} / \mathrm{m}^{2}$ for 
women, which were both lower than the sex-specific cutoff values for the PMI used as criteria for sarcopenia in Asian adults [23]. Of the 74 patients with recurrent pancreatic cancer, 65 (87.8\%) had low PMIs and were diagnosed with sarcopenia based on these criteria.

Table 1 shows the correlations of the clinicopathological characteristics between patients with low PMI (the sarcopenia group) and those with normal PMI (the nonsarcopenia group). Body mass index at the time of recurrence and lymphatic vessel invasion were significantly correlated between the two groups.

Figure 1 shows the post-recurrence survival curves for sarcopenia at the time of recurrence. The 2-year postrecurrence survival rates and median survival times after recurrence in patients with sarcopenia were $16.2 \%$ and 9.6 months, respectively, which were significantly worse than those in patients without sarcopenia $(50.0 \%, 15.5$ months, respectively; $P=0.034$ ).

Multivariate analysis revealed that sarcopenia at the time of recurrence was an independent prognostic factor (hazard ratio $[\mathrm{HR}] 3.094, P=0.043$ ), along with the neutrophil-to-lymphocyte ratio (HR 2.357, $P=0.004$ ), time to recurrence after pancreatectomy (HR 2.940, $P=0.001$ ), and chemotherapy after recurrence (HR 0.348, $P=0.005$ ) in patients with recurrent pancreatic cancer (Table 2).

Using sarcopenia and time of recurrence after pancreatectomy, which were independent prognostic factors, we divided the combination of sarcopenia and time of recurrence into three groups as follows: non-sarcopenia and late recurrence (group A; $n=5$ ), non-sarcopenia and early recurrence or sarcopenia and late recurrence (group B; $n=29$ ), and sarcopenia and early recurrence (group $C ; n=40$ ).

The 2-year post-recurrence survival rates were $75.0 \%$, $29.7 \%$, and $7.5 \%$ in groups $\mathrm{A}, \mathrm{B}$, and $\mathrm{C}$, respectively. The median survival times after recurrence differed significantly at 15.5 months for group $\mathrm{B}$ and 6.3 months for group $\mathrm{C}$ and were unmet in group A $(P<0.001$, Fig. 2$)$. The AUC of the combination of sarcopenia and time of recurrence for predicting 2-year survival was 0.763 (Fig. 3a), which was much higher than that of sarcopenia alone (0.622, Fig. 3b).

Thus, the combination of sarcopenia and time of recurrence was more useful than sarcopenia alone for predicting the prognoses of patients with recurrent pancreatic cancer.

\section{Discussion}

This study showed that sarcopenia at the time of recurrence was an independent, unfavorable prognostic factor in patients with recurrent pancreatic cancer. Additionally, the combination of sarcopenia at the time of recurrence and time to recurrence after pancreatectomy more accurately predicted post-recurrent prognoses in patients who underwent surgery for pancreatic cancer than did sarcopenia alone. These findings indicating an association with prognosis after recurrence in patients with recurrent pancreatic cancer are of great importance because few studies have evaluated this issue.

Skeletal muscle loss negatively affects the outcomes of various diseases such as chronic diseases and many cancers $[11-15,26,27]$.

Table 1 Clinicopathological characteristics of recurrent pancreatic cancer patients with sarcopenia and without sarcopenia

\begin{tabular}{|c|c|c|c|}
\hline Characteristics & Sarcopenia group $(n=65)$ & Non-sarcopenia group $(n=9)$ & $P$ value \\
\hline Age at time of recurrence, year, median (range) & $73.0(44-85)$ & $68.0(53-80)$ & 0.529 \\
\hline Sex, male $(n, \%)$ & $44(67.7 \%)$ & $5(55.6 \%)$ & 0.476 \\
\hline Body mass index at the time of recurrence, median (range), $\mathrm{kg} / \mathrm{m}^{2}$ & $18.9(13.3-26.8)$ & $23.4(19.3-27.9)$ & $<0.001$ \\
\hline Primary tumor location (pancreatic head, \%) & $42(64.6 \%)$ & $6(66.7 \%)$ & 1.000 \\
\hline Primary tumor size, median (range), $\mathrm{mm}$ & $28.0(5-60)$ & $30.0(25-35)$ & 0.466 \\
\hline Lymph node involvement (present, \%) & $45(69.2 \%)$ & $7(77.8 \%)$ & 0.716 \\
\hline Histological grading $\left(\mathrm{G} 1^{\mathrm{a}}, \%\right)$ & $30(46.2 \%)$ & $6(66.7 \%)$ & 0.302 \\
\hline Time to recurrence after pancreatectomy (< 12 months, \%) & $25(38.5 \%)$ & $5(55.6 \%)$ & 0.471 \\
\hline Lymphatic vessel invasion (present, \%) & $23(35.9 \%)$ & $7(77.8 \%)$ & 0.027 \\
\hline Blood vessel invasion (present, \%) & $27(41.5 \%)$ & $6(66.7 \%)$ & 0.176 \\
\hline Perineural invasion (present, \%) & $9(13.8 \%)$ & $2(22.2 \%)$ & 0.615 \\
\hline Initial site of recurrence (distant, \%) & $41(63.1 \%)$ & $5(55.6 \%)$ & 0.722 \\
\hline Chemotherapy after recurrence (present, \%) & $49(75.4 \%)$ & $8(88.9 \%)$ & 0.675 \\
\hline Neutrophil-lymphocyte ratio, median (range) & $1.94(0.36-18.60)$ & $1.62(0.26-2.63)$ & 0.378 \\
\hline Serum CA19-9 levels at time of recurrence, median (range), $\mathrm{U} / \mathrm{ml}$ & $206.5(0.1-20,460)$ & $92.1(10.2-1843)$ & 0.669 \\
\hline
\end{tabular}

Continuous variables are expressed as the median and range

CA19-9 carbohydrate antigen 19-9

${ }^{\mathrm{a}} \mathrm{G} 1$, well-differentiated 


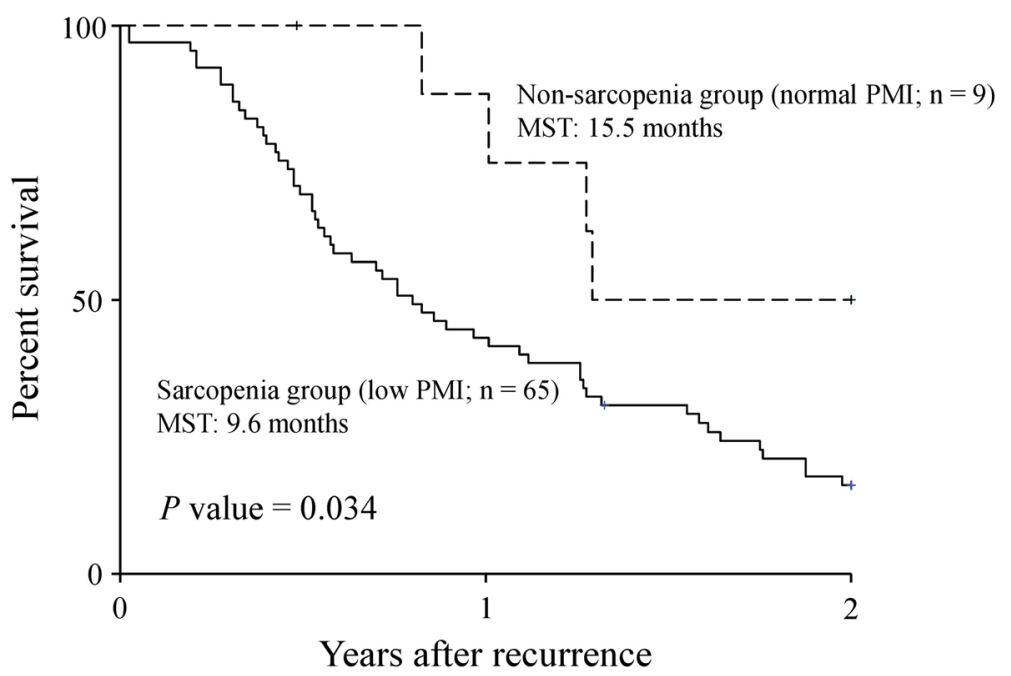

Fig. 1 Two-year post-recurrence overall survival curves in recurrent pancreatic cancer patients. Patients with low PMI (sarcopenia group) and with normal PMI (non-sarcopenia group) are compared. PMI, psoas muscle index; MST, median survival time

In pancreatic cancer, preoperative skeletal muscle loss is closely correlated with overall survival [18-20]. However, the prognostic significance of skeletal muscle loss, that is, sarcopenia, at the time of recurrence has remained unclear. In the present study, skeletal muscle loss at the time of recurrence was a significant prognostic factor in patients with recurrent pancreatic cancer.

The mechanism for the association between skeletal muscle loss and prognosis in cancer patients remains unclear. Skeletal muscle is the largest organ in the human body, accounting for more than $40 \%$ of the adult human body weight [9]. Skeletal muscle is also a secretory organ, and accumulating data have shown that muscle cells produce and secrete several hundreds of cytokines and other peptides, termed myokines, which influence various systemic responses [28].

Among numerous myokines, myostatin, a member of the transforming growth factor- $\beta$ (TGF- $\beta$ ) superfamily,

Table 2 Univariate and multivariate analyses of prognostic factors for overall survival among patients with recurrent pancreatic cancer

\begin{tabular}{|c|c|c|c|c|c|c|}
\hline \multirow[t]{2}{*}{ Variables } & \multicolumn{3}{|c|}{ Univariate analysis } & \multicolumn{3}{|c|}{ Multivariate analysis } \\
\hline & $H R$ & $95 \% \mathrm{Cl}$ & $P$ value & $H R$ & $95 \% \mathrm{Cl}$ & $P$ value \\
\hline Age at time of recurrence ( $\geq 75$ vs. $<75$ ) & 0.886 & $0.521-1.507$ & 0.655 & & & \\
\hline Sex (male vs. female) & 0.875 & $0.505-1.515$ & 0.633 & & & \\
\hline BMl at the time of recurrence $\left(<21.8 \mathrm{~kg} / \mathrm{m}^{2} \mathrm{vs} . \geq 21.8 \mathrm{~kg} / \mathrm{m}^{2}\right)$ & 2.249 & $1.186-4.264$ & 0.013 & 1.203 & $0.608-2.380$ & 0.596 \\
\hline Smoking status at the time of recurrence (current or former vs. never) & 0.903 & $0.478-1.707$ & 0.753 & & & \\
\hline Primary tumor location (head vs. body and tail) & 0.876 & $0.512-1.499$ & 0.630 & & & \\
\hline Primary tumor size ( $\geq 28.9 \mathrm{~mm}$ vs. $<28.9 \mathrm{~mm}$ ) & 1.396 & $0.826-2.361$ & 0.213 & & & \\
\hline Histological grading for primary tumor (G1 vs. other) & 0.729 & $0.435-1.222$ & 0.230 & & & \\
\hline Lymph node metastasis at initial surgery (present vs. absent) & 1.624 & $0.911-2.895$ & 0.100 & 1.560 & $0.819-2.972$ & 0.176 \\
\hline Surgical margin at the initial resection (present vs. absent) & 0.940 & $0.445-1.986$ & 0.871 & & & \\
\hline Serum CA19-9 level at time of recurrence $(\geq 107.95 \mathrm{U} / \mathrm{ml}$ vs. $<107.95 \mathrm{U} / \mathrm{ml})$ & 0.931 & $0.548-1.583$ & 0.793 & & & \\
\hline $\mathrm{NLR}(\geq 1.69 \mathrm{~mm}$ vs. $<1.69 \mathrm{~mm})$ & 2.544 & $1.460-4.434$ & 0.001 & 2.357 & $1.314-4.228$ & 0.004 \\
\hline Time to recurrence after pancreatectomy ( $<12$ months [early] vs. $\geq 12$ months [late]) & 2.618 & $1.489-4.604$ & 0.001 & 2.940 & $1.551-5.573$ & 0.001 \\
\hline Initial site of recurrence (distant vs. local) & 1.227 & $0.717-2.100$ & 0.456 & & & \\
\hline Chemotherapy after recurrence (present vs. absent) & 0.489 & $0.266-0.898$ & 0.021 & 0.348 & $0.165-0.732$ & 0.005 \\
\hline Sarcopenia at time of recurrence (present vs. absent) & 2.846 & $1.029-7.871$ & 0.044 & 3.094 & $1.035-9.248$ & 0.043 \\
\hline
\end{tabular}




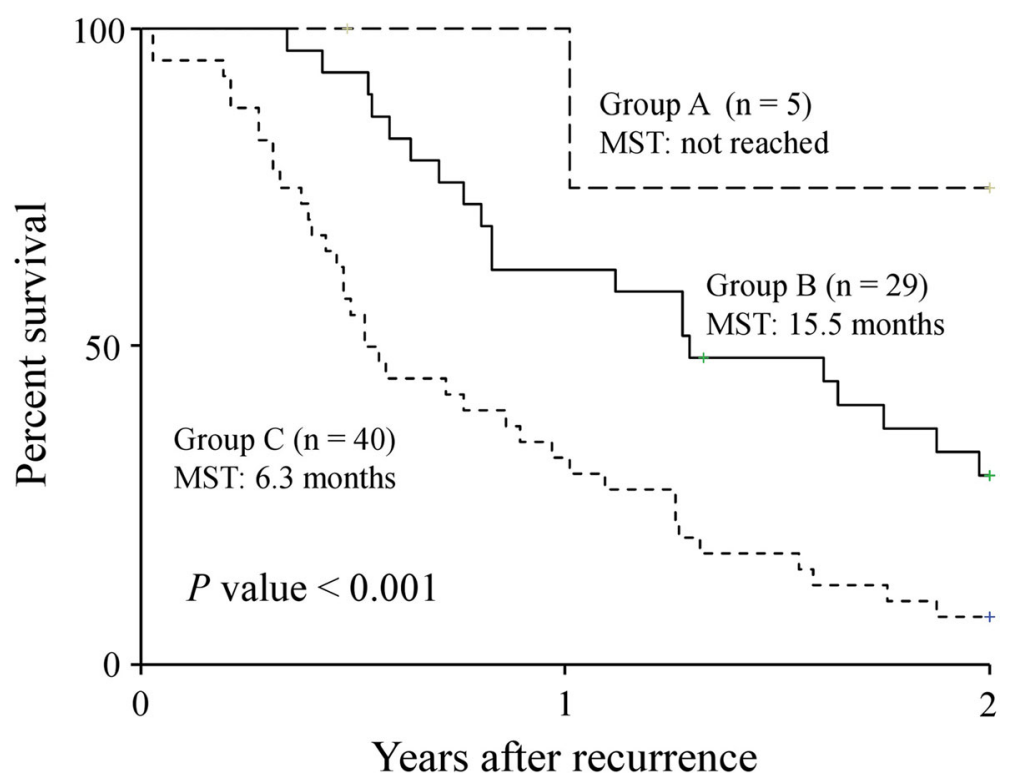

Fig. 2 Two-year post-recurrence overall survival curves. Curves are according to the combination of sarcopenia at the time of recurrence after pancreatectomy and time of recurrence. Group A, non-sarcopenia and late recurrence; group B, non-sarcopenia and early recurrence or sarcopenia and late recurrence; group C, sarcopenia and early recurrence. MST, mean survival time

is a key regulator of skeletal muscle mass. Myostatin inactivation increases skeletal muscle volume. In contrast, activated myostatin decreases skeletal muscle volume [29]. TGF- $\beta$ is a multifunctional regulatory factor and responds to tumor cells by regulating tumor development by suppressing epithelial cell tumorigenesis early in the carcinogenic process via the TGF- $\beta$-SMAD pathway. In advanced stages, however, TGF- $\beta$ switches to promote tumor progression. Increased TGF- $\beta$ expression by tumor cells promotes tumor progression by enhancing migration, invasion, and survival of tumor cells by stimulating extracellular matrix deposition and tissue fibrosis, perturbing immune and inflammatory functions, and stimulating angiogenesis [30, 31]. Therefore, high TGF- $\beta$ expression can promote muscle wasting and tumor progression in late-stage cancer patients. In pancreatic cancer, TGF- $\beta$ plays a paradoxical role by both suppressing and promoting tumors. Previous studies showed that patients with unresectable pancreatic cancer had increased soluble TGF- $\beta$; thus, TGF- $\beta$ was identified as a prognostic factor $[32,33]$.

Proinflammatory cytokines, such as interleukin (IL)-1, IL-6, and tumor necrosis factor alpha (TNF- $\alpha$ ), cause skeletal muscle proteolysis by suppressing muscle genes a

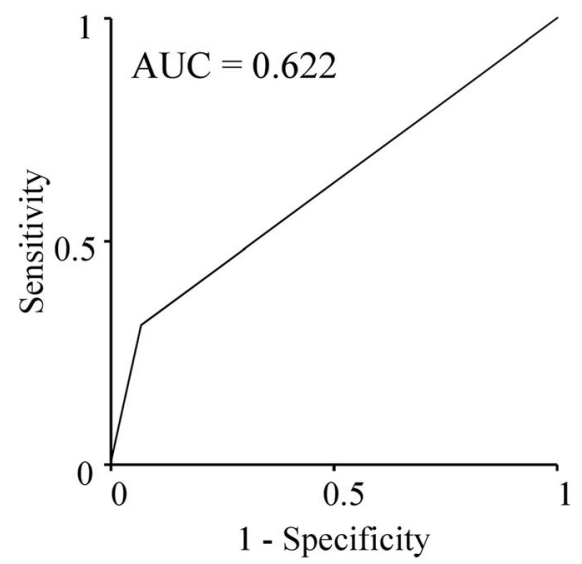

b

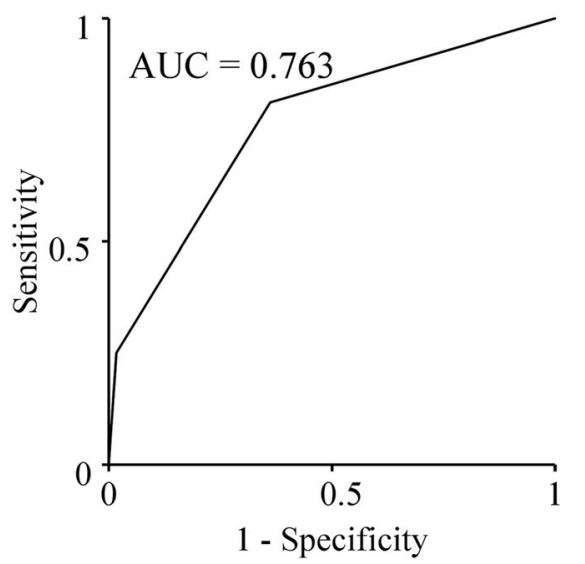

Fig. 3 Receiver operating characteristic curves and AUCs of sarcopenia (a) and the combination of sarcopenia and time of recurrence after pancreatectomy (b) for predicting 2-year survival after recurrence of pancreatic cancer. AUC, area under the curve 
and activating ubiquitin-proteasome-mediated proteolysis and are closely associated with both sarcopenia and cancer-related cachexia [34].

A strong relationship exists between skeletal muscles and the immune system. Skeletal muscle contains more leukocytes, such as CD8+ T cells, regulatory $\mathrm{T}$ cells, and neutrophils, which play important roles in antitumor immunity and are the same as those in the total blood of human adults [35]. Hence, skeletal muscle wasting induces decreased leukocyte numbers and impairs tumor immunity in cancer patients with sarcopenia, which in turn results in tumor progression. Therefore, these relationships may explain the correlation between sarcopenia at the time recurrence and poor prognoses in the current study.

Post-recurrence overall survival in an early recurrence group after curative surgery for pancreatic cancer was reported to be significantly worse than that of the late recurrence group [25]. In that study, larger tumor sizes, high preoperative serum carbohydrate antigen 19-9 levels, poor differentiation on histological grading, presence of microscopic lymphovascular invasion, and highly positive lymph node ratios were reported as risk factors for early recurrence. Another study found more distant metastasis in patients whose pancreatic cancer recurred within 12 months [36]. These findings suggest that patients with early recurrence already had more aggressive tumor biology that led to shorter recurrence-free survival after the initial surgery and a more rapid progression to death. In our study, both sarcopenia and early recurrence were independent prognostic factors in patients whose pancreatic cancer recurred. Sarcopenia is regulated by factors related to patients' physical and functional conditions, whereas time to recurrence is regulated by tumor behavioral factors. We hypothesized that the combination of these two factors regulated by different factors might better predict the prognosis in patients with recurrent pancreatic cancer than can sarcopenia alone. The combination of sarcopenia and time to recurrence predicted the prognosis in patients with recurrent pancreatic cancer more accurately than did sarcopenia alone.

This study had several limitations. First, it was retrospective with a small sample size and was conducted in a single institution, which could generate bias. No standard methods exist to precisely evaluate sarcopenia because skeletal muscle mass and strength are influenced considerably by ethnicity, body size, age, lifestyle, and cultural background. Although the criteria for sarcopenia using PMI measurement as reported by Hamaguchi et al. were used to evaluate sarcopenia in this study, these criteria were determined from data from healthy Asian young-adult donors for living donor liver transplantation. Furthermore, the participants in this study were all of Asian ethnicity. These facts limit the generalizability of our results; therefore, the optimal PMI cutoff value generalizing the definition of sarcopenia in patients with recurrent pancreatic cancer remains unclear. A large-scale prospective study is needed to verify our results. Additionally, further studies should be conducted to define sarcopenia corresponding to patients' various conditions to more accurately evaluate sarcopenia-related events.

In conclusion, sarcopenia is a useful prognostic factor in patients with recurrent pancreatic cancer. The combination of sarcopenia and time to recurrence might more accurately predict post-recurrence survival than can sarcopenia alone. Not only systemic chemotherapy but also regular exercise and nutritional therapy after curative surgery might be needed to improve the prognosis in patients with recurrent pancreatic cancer.

\section{Abbreviations \\ AUC: Area under the curve; HR: Hazard ratio; IL: Interleukin; MST: Median survival time; PMI: Psoas muscle index; TNF-a: Tumor necrosis factor alpha}

\section{Acknowledgements}

We thank Traci Raley, MS, ELS, and Jane Charbonneau, DVM, from Edanz group (https://en-author-services.edanzgroup.com/ac) for editing a draft of this manuscript.

\section{Authors' contributions}

Study concepts: TS. Study design: TS. Data acquisition: TY, EU, and TH. Quality control of data and algorithms: KM and TM. Data analysis and interpretation: KK and NT. Statistical analysis: TS and MY. Manuscript preparation: TS. Manuscript editing: SH. Manuscript review: YF. Final approval of the article: all authors.

\section{Funding}

None

\section{Availability of data and materials}

The datasets used and analyzed during the current study are available from the corresponding author on reasonable request.

\section{Ethics approval and consent to participate}

All procedures performed in studies involving human participants were conducted in accordance with the ethical standards of the institutional review board of the ethics committee and national research committee and with the 1964 Helsinki Declaration and its later amendments. The Tottori University Hospital Ethics Committee approved this study (No. 17A135).

Consent for publication

Not applicable.

\section{Competing interests}

The authors declare that they have no competing interests.

Received: 23 May 2020 Accepted: 31 July 2020

Published online: 22 August 2020

\section{References}

1. Caan BJ, Cespedes Feliciano EM, Prado CM, Alexeeff S, Kroenke CH, Bradshaw P, Quesenberry CP, Weltzien EK, Castillo AL, Olobatuyi TA, Chen WY. Association of muscle and adiposity measured by computed tomography with survival in patients with nonmetastatic breast cancer. JAMA Oncol. 2018;4:798-804.

2. Jung AR, Roh JL, Kim JS, Kim SB, Choi SH, Nam SY, Kim SY. Prognostic value of body composition on recurrence and survival of advanced-stage head and neck cancer. Eur J Cancer. 2019;116:98-106. 
3. Purcell SA, Elliott SA, Kroenke CH, Sawyer MB, Prado CM. Impact of body weight and body composition on ovarian cancer prognosis. Curr Oncol Rep. 2016;18:8.

4. Shachar SS, Williams GR, Muss HB, Nishijima TF. Prognostic value of sarcopenia in adults with solid tumours: a meta-analysis and systematic review. Eur J Cancer. 2016:57:58-67.

5. Rosenberg $\mathbb{H}$. Summary comments. Am J Clin Nutr. 1989;50:1231-3.

6. Cruz-Jentoft AJ, Baeyens JP, Bauer JM, Boirie Y, Cederholm T, Landi F, Martin FC, Michel JP, Rolland Y, Schneider SM, et al. Sarcopenia: European consensus on definition and diagnosis: report of the European Working Group on Sarcopenia in older people. Age Ageing. 2010;39:412-23.

7. Chen LK, Liu LK, Woo J, Assantachai P, Auyeung TW, Bahyah KS, Chou MY, Chen LY, Hsu PS, Krairit O, et al. Sarcopenia in Asia: consensus report of the Asian Working Group for Sarcopenia. J Am Med Dir Assoc. 2014;15:95-101.

8. Dodson S, Baracos VE, Jatoi A, Evans WJ, Cella D, Dalton JT, Steiner MS Muscle wasting in cancer cachexia: clinical implications, diagnosis, and emerging treatment strategies. Annu Rev Med. 2011;62:265-79.

9. Argiles JM, Busquets S, Stemmler B, Lopez-Soriano FJ. Cachexia and sarcopenia: mechanisms and potential targets for intervention. Curr Opin Pharmacol. 2015;22:100-6.

10. Ryan AM, Power DG, Daly L, Cushen SJ, Ni Bhuachalla E, Prado CM. Cancerassociated malnutrition, cachexia and sarcopenia: the skeleton in the hospital closet 40 years later. Proc Nutr Soc. 2016;75:199-211.

11. Deng HY, Zha P, Peng L, Hou L, Huang KL, Li XY. Preoperative sarcopenia is a predictor of poor prognosis of esophageal cancer after esophagectomy: a comprehensive systematic review and meta-analysis. Dis Esophagus. 2019; 32.

12. Nakashima Y, Saeki H, Nakanishi R, Sugiyama M, Kurashige J, Oki E, Maehara $Y$. Assessment of sarcopenia as a predictor of poor outcomes after esophagectomy in elderly patients with esophageal cancer. Ann Surg. 2018; 267:1100-4.

13. Kawamura T, Makuuchi R, Tokunaga M, Tanizawa Y, Bando E, Yasui $H$, Aoyama T, Inano T, Terashima M. Long-term outcomes of gastric cancer patients with preoperative sarcopenia. Ann Surg Oncol. 2018;25:1625-32.

14. Kudou K, Saeki H, Nakashima Y, Edahiro K, Korehisa S, Taniguchi D, Tsutsumi R, Nishimura S, Nakaji Y, Akiyama S, et al. Prognostic significance of sarcopenia in patients with esophagogastric junction cancer or upper gastric cancer. Ann Surg Oncol. 2017;24:1804-10.

15. Miyamoto Y, Baba Y, Sakamoto Y, Ohuchi M, Tokunaga R, Kurashige J, Hiyoshi Y, Iwagami S, Yoshida N, Yoshida M, et al. Sarcopenia is a negative prognostic factor after curative resection of colorectal cancer. Ann Surg Oncol. 2015;22:2663-8.

16. Kamisawa T, Wood LD, Itoi T, Takaori K. Pancreatic cancer. Lancet. 2016;388: 73-85.

17. Gillen S, Schuster T, Meyer Zum Buschenfelde C, Friess H, Kleeff J. Preoperative/neoadjuvant therapy in pancreatic cancer: a systematic review and meta-analysis of response and resection percentages. PLoS Med. 2010; 7:e1000267

18. Carrara G, Pecorelli N, De Cobelli F, Cristel G, Damascelli A, Beretta L, Braga M. Preoperative sarcopenia determinants in pancreatic cancer patients. Clin Nutr. 2017:36:1649-53.

19. Choi MH, Yoon SB, Lee K, Song M, Lee IS, Lee MA, Hong TH, Choi MG Preoperative sarcopenia and post-operative accelerated muscle loss negatively impact survival after resection of pancreatic cancer. J Cachexia Sarcopenia Muscle. 2018;9:326-34

20. Okumura S, Kaido T, Hamaguchi Y, Fujimoto Y, Masui T, Mizumoto M, Hammad A, Mori A, Takaori K, Uemoto S. Impact of preoperative quality as well as quantity of skeletal muscle on survival after resection of pancreatic cancer. Surgery. 2015;157:1088-98.

21. Kurita Y, Kobayashi N, Tokuhisa M, Goto A, Kubota K, Endo I, Nakajima A Ichikawa Y. Sarcopenia is a reliable prognostic factor in patients with advanced pancreatic cancer receiving FOLFIRINOX chemotherapy. Pancreatology. 2019;19:127-35.

22. Basile D, Parnofiello A, Vitale MG, Cortiula F, Gerratana L, Fanotto V, Lisanti C, Pelizzari G, Ongaro E, Bartoletti M, et al. The IMPACT study: early loss of skeletal muscle mass in advanced pancreatic cancer patients. J Cachexia Sarcopenia Muscle. 2019;10:368-77.

23. Hamaguchi Y, Kaido T, Okumura S, Kobayashi A, Hammad A, Tamai Y, Inagaki N, Uemoto S. Proposal for new diagnostic criteria for low skeletal muscle mass based on computed tomography imaging in Asian adults. Nutrition. 2016;32:1200-5.
24. Brierley JD, Gospodarowicz MK, Wittekind C. TNM classification of malignant tumours: John Wiley \& Sons; 2017.

25. Groot VP, Gemenetzis G, Blair AB, Rivero-Soto RJ, Yu J, Javed AA, Burkhart RA, Rinkes I, Molenaar IQ, Cameron JL, et al. Defining and predicting early recurrence in 957 patients with resected pancreatic ductal adenocarcinoma. Ann Surg. 2019;269:1154-62.

26. Bone $A E$, Hepgul N, Kon S, Maddocks M. Sarcopenia and frailty in chronic respiratory disease. Chron Respir Dis. 2017;14:85-99.

27. Lai S, Muscaritoli M, Andreozzi P, Sgreccia A, De Leo S, Mazzaferro S, Mitterhofer AP, Pasquali M, Protopapa P, Spagnoli A, et al. Sarcopenia and cardiovascular risk indices in patients with chronic kidney disease on conservative and replacement therapy. Nutrition. 2019;62:108-14.

28. Pedersen BK, Febbraio MA. Muscles, exercise and obesity: skeletal muscle as a secretory organ. Nat Rev Endocrinol. 2012;8:457-65.

29. Rodriguez J, Vernus B, Chelh I, Cassar-Malek I, Gabillard JC, Hadj Sassi A, Seiliez I, Picard B, Bonnieu A. Myostatin and the skeletal muscle atrophy and hypertrophy signaling pathways. Cell Mol Life Sci. 2014;71:4361-71.

30. Morikawa M, Derynck R, Miyazono K. TGF-beta and the TGF-beta family: context-dependent roles in cell and tissue physiology. Cold Spring Harb Perspect Biol. 2016;8.

31. Jazag A, ljichi H, Kanai F, Imamura T, Guleng B, Ohta M, Imamura J, Tanaka Y, Tateishi K, Ikenoue T, et al. Smad4 silencing in pancreatic cancer cell lines using stable RNA interference and gene expression profiles induced by transforming growth factor-beta. Oncogene. 2005;24:662-71.

32. Truty MJ, Urrutia R. Basics of TGF-beta and pancreatic cancer. Pancreatology. 2007;7:423-35

33. Park H, Bang JH, Nam AR, Park JE, Jin MH, Bang YJ, Oh DY. The prognostic role of soluble TGF-beta and its dynamics in unresectable pancreatic cancer treated with chemotherapy. Cancer Med. 2020;9:43-51.

34. Lenk K, Schuler G, Adams V. Skeletal muscle wasting in cachexia and sarcopenia: molecular pathophysiology and impact of exercise training. J Cachexia Sarcopenia Muscle. 2010;1:9-21.

35. Tidball JG. Regulation of muscle growth and regeneration by the immune system. Nat Rev Immunol. 2017;17:165-78.

36. Nishio K, Kimura K, Amano R, Yamazoe S, Ohrira G, Nakata B, Hirakawa K, Ohira M. Preoperative predictors for early recurrence of resectable pancreatic cancer. World J Surg Oncol. 2017:15:16.

\section{Publisher's Note}

Springer Nature remains neutral with regard to jurisdictional claims in published maps and institutional affiliations.

Ready to submit your research? Choose BMC and benefit from:

- fast, convenient online submission

- thorough peer review by experienced researchers in your field

- rapid publication on acceptance

- support for research data, including large and complex data types

- gold Open Access which fosters wider collaboration and increased citations

- maximum visibility for your research: over $100 \mathrm{M}$ website views per year

At $\mathrm{BMC}$, research is always in progress.

Learn more biomedcentral.com/submissions 